\title{
Facile Synthesis of a Zinc Oxide Nanoparticle by electrochemical method
}

\author{
Aishah Abdul Jalil ${ }^{1,2^{*}}$, Sugeng Triwahyono ${ }^{3,4}$ Nur Hanis Hayati Hairom² and Nurul Aini Mohamed Razali ${ }^{2}$ \\ ${ }^{1}$ Institute Hydrogen Economy, Universiti Teknologi Malaysia, 81310 UTM Johor Bahru, Johor, Malaysia \\ ${ }^{2}$ Department of Chemical Eng., Faculty of Chemical Eng., Universiti Teknologi Malaysia, 81310 UTM Johor Bahru, Johor, Malaysia \\ ${ }^{3}$ Department of Chemistry, Faculty of Science, Universiti Teknologi Malaysia, 81310 UTM Johor Bahru, Johor, Malaysia \\ ${ }^{4}$ Ibnu Sina Institute for Fundamental Science Studies, Universiti Teknologi Malaysia, 81310 UTM Johor Bahru, Johor, Malaysia \\ *Corresponding Author: aishah@cheme.utm.my (A.A. Jalil)
}

\section{Article history :}

Received 26 February 2014

Revised 7 June 2014

Accepted 29 June 2014

Available online 17 August 2014

\section{GRAPHICAL ABSTRACT}

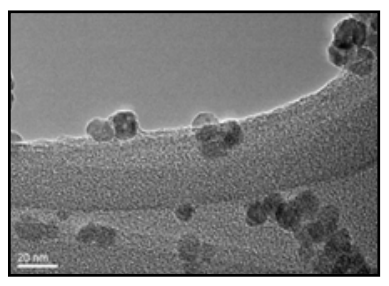

\section{ABSTRACT}

An electrogenerated zinc oxide (EGZnO/Naph) nanoparticle was successfully synthesized by electrolysis of a $\mathrm{N}, \mathrm{N}$-dimethylformamide (DMF) solution containing naphthalene and a supporting electrolyte in a onecompartment cell fitted with a platinum cathode and a zinc anode. X-ray diffraction (XRD) and transmission electron microscopy (TEM) studies showed that the EGZnO/Naph consists of pure single crystalline wurtzite of hexagonal structure with average diameters of 10-15 nm. The BET surface area of the EGZnO/Naph was $65 \mathrm{~m}^{2} / \mathrm{g}$, which is 15 times larger than that of commercial $\mathrm{ZnO}$ powder. The zinc oxide was also confirmed by Fourier transform infrared (FTIR) results which showed vibrational bands at 500 and $434 \mathrm{~cm}^{-1}$. Furthermore, the absorption peak of the EGZnO/Naph obtained at $366 \mathrm{~nm}(3.35 \mathrm{eV})$, is very close to the band gap of the $\mathrm{ZnO} 1 \mathrm{~s}-1 \mathrm{~s}$ electron transition $(3.37 \mathrm{eV})$. Based on these results, this study reports a new pathway to synthesize nanosize of $\mathrm{ZnO}$ particle using a simple electrochemical process.

Keywords: Nanostructures, Chemical synthesis, Electron microscopy, Infrared spectroscopy, X-ray diffraction

(C) 2014 Penerbit UTM Press. All rights reserved http://dx.doi.org/10.11113/mjfas.v10n3.319

\section{INTRODUCTION}

Nanostructured zinc oxide $(\mathrm{ZnO})$ has become one of the most attractive materials in recent years because of its electrical, catalytic and optical/electronic properties [1-4]. Size, shape, and surface morphology of nanoparticle play pivotal roles in controlling the physical, chemical, optical and electronic properties of this nanoscopic material [5]. Many methods have been studied to synthesize $\mathrm{ZnO}$ nanostructures, since their physical and chemical properties are strongly influenced by the method of synthesis. Some of the successful methods, including microwave irradiation [6], hydrothermal [7], sonochemical [8] and sol-gel [9,10] processes, have been reported in the literature. However, in most of these works, the synthesized $\mathrm{ZnO}$ particles have an average diameters of $100-600 \mathrm{~nm}$, whereas only a few published reports presented average diameters of 20-50 nm of $\mathrm{ZnO}[9,10]$. In addition, simple and mild conditions for the preparation of high-quality $\mathrm{ZnO}$ nanostructures are required. Undoubtedly, one of the most promising methods for such synthesis is electrolysis. This method is a simple, inexpensive and safe option, since the electrons are considered clean reagents in contrast to the harmful oxidative or reducing agents used otherwise [11].

Tokuda et al. have reported a new and simple preparation method for highly reactive electrogenerated zinc (EGZn/Naph) using a platinum cathode and a zinc anode in the presence of naphthalene as a mediator. This
EGZn/Naph was an aggregation of very fine particles that passed through usual filter paper and did not precipitate, even after being kept overnight. It was efficiently used in the cross-coupling of halide compounds for the synthesis of anti-inflammatory agent precursors [12]. Due to the physical observation and high reactivity of this EGZn/Naph, we expect that it is made up of nanoparticles with a larger surface area than that of EGZn [13-17] and commercial zinc powder. However, the nature and structure of EGZn/Naph is not clear at the present stage, since it undergoes immediate oxidation when exposed to air to form EGZnO/Naph. In a parallel study, we studied the chemical and physical properties of EGZnO/Naph. In this paper we report the characterization of this nanoscopic material by XRD, FESEM, TEM, FTIR, $\mathrm{N}_{2}$ physisorption, and UV spectroscopy. The activity of EGZnO/Naph has been enhanced and made useful for any practical application compared to commercial $\mathrm{ZnO}$ due to its increased surface area and to changes in surface properties, such as surface defects [17-18]. Here, we present the preparation of much smaller high purity $\mathrm{ZnO}$ nanoparticles using our simple, low energy consumption and green electrochemical method.

\section{EXPERIMENTAL}

Electrogenerated highly reactive EGZn/Naph (6 mmol) was prepared via the electrolysis of a $N-N$ dimethylformamide solution $(10 \mathrm{~mL})$ containing $0.1 \mathrm{M}$ 
tetraethylammonium perchlorate $\left(\mathrm{Et}_{4} \mathrm{NClO}_{4}, 230 \mathrm{mg}\right)$ and a naphthalene mediator (12 $\mathrm{mmol})$ in a one-compartment cell fitted with a platinum plate cathode $\left(2 \times 2 \mathrm{~cm}^{2}\right)$ and a zinc plate anode $\left(2 \times 2 \mathrm{~cm}^{2}\right)$. At the end of the electrolysis, the black solution was filtered and calcined at $550{ }^{\circ} \mathrm{C}$ to give the white powder of the EGZnO/Naph, which was then characterized.

The crystalline structure of the EGZnO/Naph was investigated via X-ray diffractometry (XRD) using a Bruker Advance D8 Siemens 5000 diffractometer with $\mathrm{Cu} \mathrm{K \alpha}$ radiation $(\lambda=0.15418 \AA, 40 \mathrm{kV}, 40 \mathrm{~mA})$ over the diffraction angle $(2 \theta)$ at range of $2-90^{\circ}$. While, the surface areas were calculated according to the method of Brunauer, Emmett and Teller (BET). The morphologies and nanostructures were observed with a Transmission Electron Microscope (TEM, JEOL JEM-2100) equipped with an Energy Dispersion X-ray Spectrometer (EDX).

The FTIR spectra were recorded using a PerkinElmer Spectrum One FTIR spectrometer with a resolution of $4 \mathrm{~cm}^{-1}$ in the mid IR region $\left(400-4000 \mathrm{~cm}^{-1}\right)$. The measurements were made in the solid phase using $\mathrm{KBr}$ pellets. DRUV-visible absorption spectra were recorded using UV-Vis Diffuse Reflectance (Perkin-Elmer Lambda 900 spectrometer). The scanning wavelength range was 300-500 nm.

\section{RESULTS \& DISCUSSION}

\subsection{X-ray diffraction \& BET surface area}

Fig. 1 shows the XRD pattern of $\mathrm{ZnO}$ nanoparticles. Fig. 1(b) shows the XRD pattern of a typical sample prepared via the electrolysis of a DMF solution, containing naphthalene as a mediator in a cell, fitted with a platinum cathode and zinc anode at $0^{\circ} \mathrm{C}$. The diffractograms of the sample were quite similar to those of commercial $\mathrm{ZnO}$ (Fig. $1(\mathrm{c})$ ), which are well-matched with the typical single crystalline wurtzite hexagonal phase bulk ZnO (JCPDS file No. 36-1451, Fig. 1(a)) [19]. No characteristic peaks of other impurities were detected in the pattern. The sharp diffraction peaks indicate a good crystallinity of the EGZnO/Naph [20]. The lattice constants are calculated to be $a=0.32427 \mathrm{~nm}$ (utilizing the observed (100) diffraction) and $\mathrm{c}=0.51948 \mathrm{~nm}$ (utilizing the observed (101) diffraction), which are slightly smaller than $0.32498 \mathrm{~nm}$ and $0.52066 \mathrm{~nm}$ for the bulk $\mathrm{ZnO}$ powder. This indicates that by using our simple electrolysis method, we have succeeded in the producing of high purity of $\mathrm{ZnO}$ nanoparticles.

The surface areas of commercial $\mathrm{ZnO}$ and the EGZnO/Naph were measured to be 4.40 and $65.56 \mathrm{~m}^{2} / \mathrm{g}$, respectively. Parallel to the TEM results, the BET results show that the surface area of the EGZnO/Naph is 15 times higher than that of commercial $\mathrm{ZnO}$.

\section{$3.2 \quad$ FTIR}

The quality and composition of the EGZnO/Naph were characterized using FTIR spectroscopy at room temperature in the range of $400-4000 \mathrm{~cm}^{-1}$ as shown in Fig. 2. The obtained spectrum shows two absorption bands at 500 and $434 \mathrm{~cm}^{-1}$, which are the typical characteristic bands of the wurtzite hexagonal phase pure $\mathrm{ZnO}$ [21-22]. The band at $\sim 3460 \mathrm{~cm}^{-1}$ is related to the existence of a hydroxyl group, may be due to its high reactivity. Furthermore, the bands at 1634 and $1100 \mathrm{~cm}^{-1}$ belong to CONH and C-N, respectively.

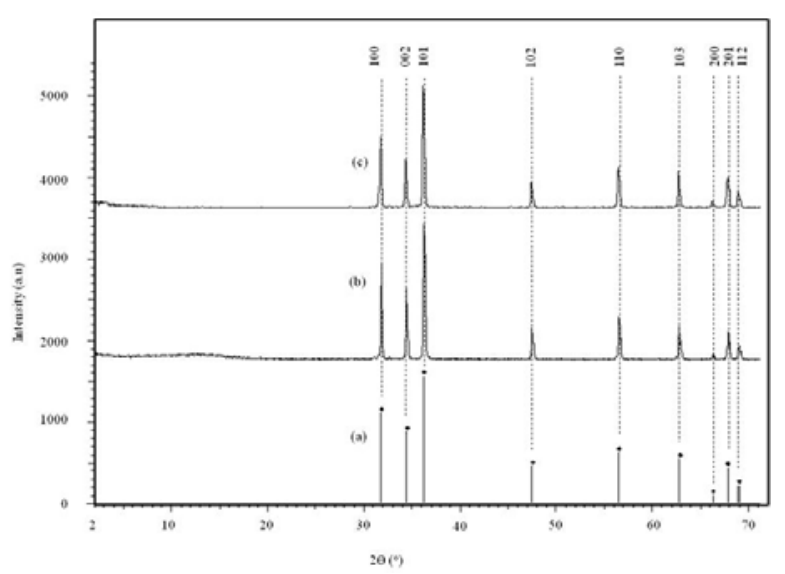

Fig. 1 XRD patterns of the $\mathrm{ZnO}$ samples: (a) $\mathrm{ZnO}$ peaks (b) EGZnO/Naph (c) Commercial $\mathrm{ZnO}$

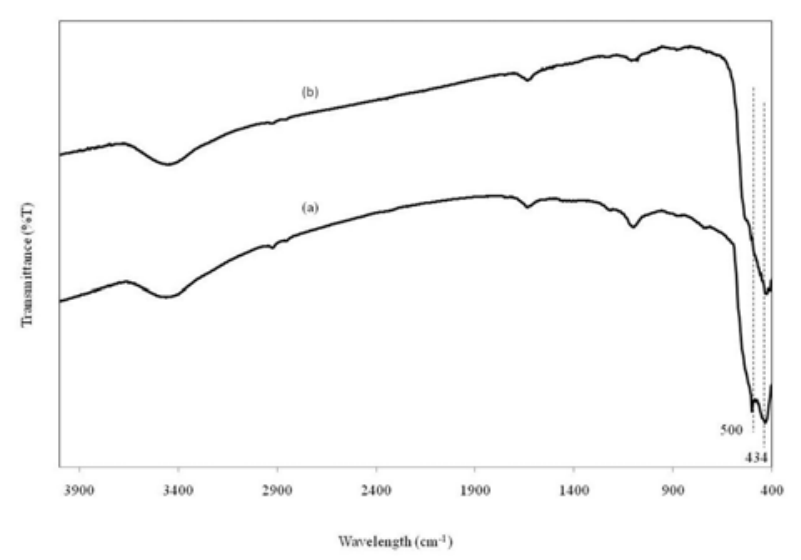

Fig. 2 FTIR image of the ZnO samples: (a) EGZnO/Naph (b) Commercial $\mathrm{ZnO}$

\subsection{TEM observation}

Fig. 3(b) shows TEM images with high magnification, from which it can be clearly seen that the EGZnO/Naph consisted of particles $10-15 \mathrm{~nm}$ in size, which is over 10 times smaller than that of commercial $\mathrm{ZnO}$ $(100-500 \mathrm{~nm})$, be evidence in Fig. 3(a) . Fig. 3(c) is an enlargement of Fig. 3(b), and illustrates the high-resolution transmission electron microscopic (HRTEM) image of the EGZnO/Naph. More detailed insight from the HRTEM image shows that the interplanar spacing of the EGZnO/Naph is approximately $0.2595 \mathrm{~nm}$, which may correspond to the distance between two (002) planes of 
hexagonal $\mathrm{ZnO}$, indicating that the EGZnO/Naph nanosphere is single crystalline in nature [23]. The formation route of this $\mathrm{EGZnO} / \mathrm{Naph}$ is similar to the mechanism which was reported by Tokuda et al [12].

Fig. 4 illustrates an EDX analysis of the EGZnO/Naph, in which it can be seen that the nanosphere is in high purity and contains only $\mathrm{Zn}$ and $\mathrm{O}$ without the presence of a contaminant. The atomic ratios of $\mathrm{Zn}$ and $\mathrm{O}$ are calculated to be approximately $1: 1$. To the best of our knowledge, this is the first report of the synthesis of a high purity $\mathrm{ZnO}$ nanosphere with an average particle size of less than $20 \mathrm{~nm}$ using an electrochemical method.

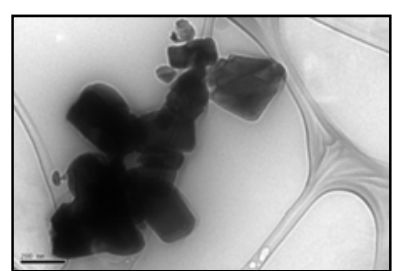

(a)

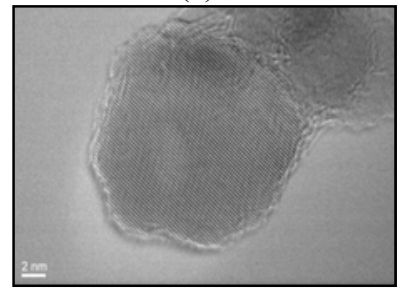

(c)

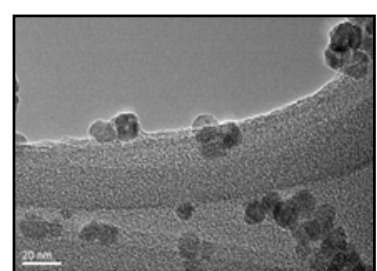

(b)

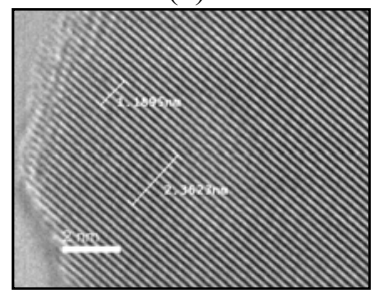

(d)
Fig. 3 TEM micrographs of the $\mathrm{ZnO}$ : (a) Commercial $\mathrm{ZnO}$ (b) EGZnO/Naph (c, d) HRTEM image of EGZnO/Naph.

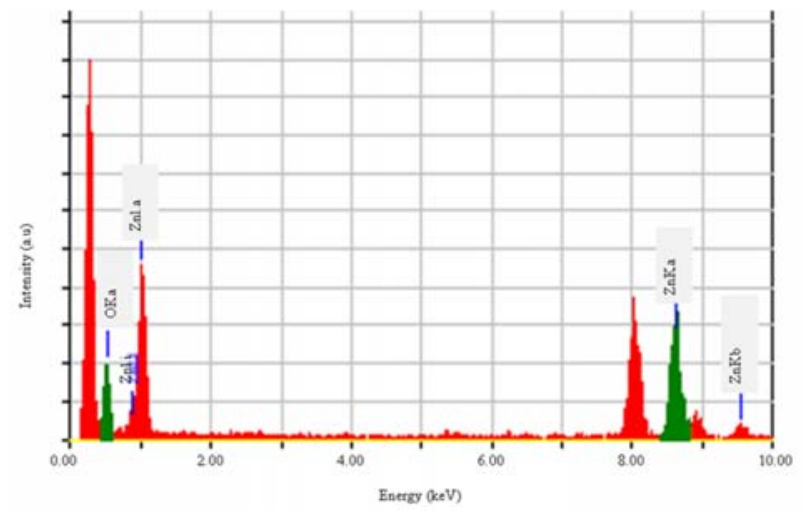

Thin Film Standardless Standardless Quantitative Analysis Fitting Coefficient: 0.6999

\begin{tabular}{|l|l|l|l|l|l|l|}
\hline Element & $(\mathrm{keV})$ & Mass\% & Counts & Error\% & Atom\% & $\mathrm{K}$ \\
\hline O K & 0.525 & 20.15 & 471.77 & 0.06 & 50.76 & 0.8256 \\
\hline Zn K (Ref.) & 8.630 & 79.85 & 1543.74 & 0.05 & 49.24 & 1.0000 \\
\hline Total & & 100.00 & & & 100.00 & \\
& & & & & & \\
\hline
\end{tabular}

Fig. 4 Energy Dispersive X-ray (EDX) spectra of the EGZnO/Naph

\subsection{DRUV-visible}

Fig. 5 depicts the typical DRUV-vis spectrum of the EGZnO/Naph measured at room temperature. A broad band can be seen at $366 \mathrm{~nm}(3.35 \mathrm{eV})$, which is very close to the band gap of the $\mathrm{ZnO} 1 \mathrm{~s}-1 \mathrm{~s}$ electron transition $(3.37 \mathrm{eV})$ [24]. Thus, this result indicates that the prepared EGZnO/Naph nanoparticles absorb visible-light as well as ultraviolet-light [22]. Therefore, EGZnO/Naph nanoparticles are predicted to be good alternatives for visible-light photocatalysis materials in practical applications, though this is still under study.

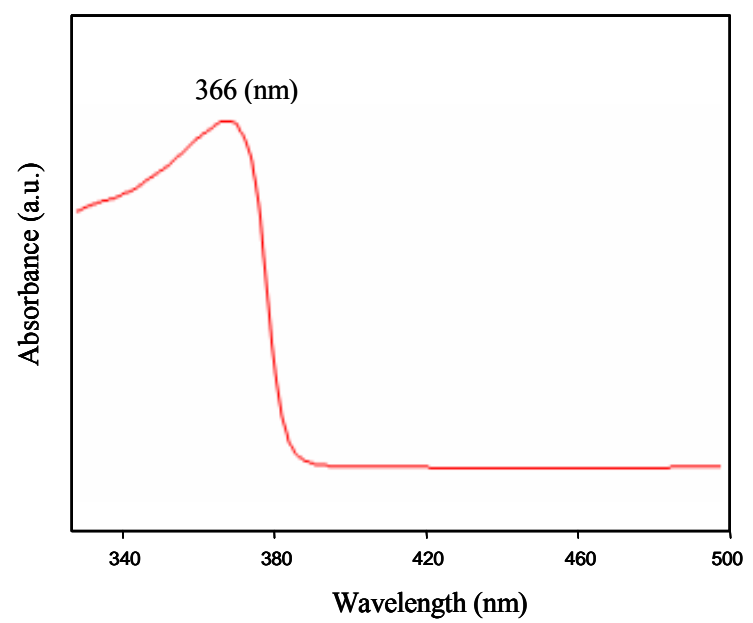

Fig. 5 DRUV-visible spectrum of EGZnO/Naph at room temperature

\section{CONCLUSION}

A nanosized EGZnO/Naph has been successfully synthesized via the simple electrolysis of a DMF solution in the presence of naphthalene. It is confirmed that the EGZnO/Naph is a pure metal oxide with a typical single crystalline wurtzite hexagonal structure. Its average diameter is $10-15 \mathrm{~nm}$ with $0.2595 \mathrm{~nm}$ of lattice spacing, and it has a surface area that is 15 times larger than that of commercial $\mathrm{ZnO}$. We have also found that the absorption peak of the EGZnO/Naph is very close to the band gap of the $\mathrm{ZnO} 1 \mathrm{~s}-1 \mathrm{~s}$ electron transition. Therefore, this simple electrolysis appears to be an excellent method for preparing high purity $\mathrm{ZnO}$ nanoparticles with much smaller particle sizes.

\section{ACKNOWLEDGEMENT}

We greatly appreciate the financial support provided by the Fundamental Research Grant (4F423) from the Ministry of Higher Education of Malaysia. We are also thankful to The Hitachi Scholarship Foundation for the support and device. 


\section{REFERENCES}

[1] N. K. Park, Y. J. Lee, S. H. Yoon, G. B. Han, S. O. Ryu, T. J. Lee, W. G. Lee, Y. J. Bae, Scripta. Mater. 59 (2008) 328.

[2] K. Ramamoorthy, M. Arivanandhan, K. Sankaranarayanan, C. Sanjeeviraja, Mater. Chem. Phys. 85 (2004) 257.

[3] Y. Gui, C. Xie, Q. Zhang, M. Hu, J. Yu, Z. Weng, J. Cryst. Growth. 289 (2006) 663.

[4] M. G. Ma, Y. J. Zhu, G. F. Cheng, Y. H. Huang, Mater. Lett. 62 (2008) 507.

[5] J.B. Reitz, E.I. Solomon, J. Am. Chem. Soc. 120 (1998) 11467.

[6] N. Takahashi, Mater. Lett. 62 (2008) 1652.

[7] Z. Yang, C. Luan, W. Zhang, A. Liu, S. Tang, Thin Solid Film. 516 (2008) 5974.

[8] A. E. Kandjani, M. F. Tabriz, B. Pourabbas, Mater. Res. Bull. 43 (2008) 645.

[9] M. Sun, W. Hao, C. Wang, T. Wang, Chem. Phys. Lett. 443 (2007) 342.

[10] M. Risti'c, S. Musi'c, M. Ivanda, S. Popovi'c, Journal of Alloys and Compounds 397 (2005) L1.

[11] M. Tokuda in Novel Trends in Electroorganic Synthesis (1995)
241, S. Torii, Ed, Kodansha, Tokyo.

[12] A. A Jalil, N. Kurono, M. Tokuda, Synlett. 12 (2001) 1944.

[13] A. A Jalil, N. Kurono, M. Tokuda, Tetrahedron. Lett. 58 (2002) 7477.

[14] A. A Jalil, N. Kurono, M. Tokuda, Synthesis. 18 (2002) 2681.

[15] M. Tokuda, N. Mimura, T. Karasawa, H. Fujita, H. Suginome, Tetrahedron. Lett. 34 (1993) 7607.

[16] M. Tokuda, N. Kurono, N. Mimura, Chem. Lett. (1996) 1091.

[17] N. Kurono, K. Sugita, S. Takasugi, M. Tokuda, Tetrahedron. Lett. 55 (1999) 6097.

[18] C. Hariharan, Appl. Catal. A 304 (2006) 55.

[19] R. Wahab, S. G. Ansari, Y. S. Kim, H. K. Seo, H. S. Shin, Appl. Surf. Sci. 253 (2007) 7622.

[20] Q. Xiao, S. Huang, J. Zhang, C. Xiao, X. Tan, J. Alloys. Compd. 459 (2008) L18.

[21] H. Kleinwechter, C. Janzen, J. Knipping, H. Wiggers, P. Roth, J. Mater. Sci. 37 (2002) 4349

[22] L. Wu, Y. Wu, W. LÜ, Physica. E 28 (2005) 76.

[23] U.N. Maiti, Sk.F. Ahmed, M.K. Mitra , K.K. Chattopadhyay, Materials Research Bulletin (2008) Article in Press.

[24] H. Wei, Y. Wu, N. Lun, C. Hu, Mater. Sci. Eng. A 393 (2005) 80. 